\title{
Nghiên cứu ISR được sử dụng trong UGC GARP 2020
}

\author{
Nguyễn Minh Hoàng \\ Trung tâm ISR, Trường ĐH Phenikaa \\ Ngày 27 tháng 11 năm 2020
}

\begin{abstract}
http://isr.phenikaa-uni.edu.vn/chitiet/su-kien 2019222759 334/nghien-cuu-isr-duoc-sudung-trong-ugc-garp-2020
\end{abstract}

Thực hành nghiên cứu khoa học tốt (GARP) là ấn phẩm định hướng công tác nghiên cứu khoa học của chính phủ Ân Độ, do Ủy ban Tài trợ Đại học (UGC) ban hành. Ân phẩm GARP 2020 có đối tác dữ liệu là Clarivate Analytics, tập đoàn dữ liệu đứng sau Journal Citation Reports và hệ thống dữ liệu ISI Web of Science [1].

Do có liên quan tới thực hành và tổ chức khoa học, bao gồm cả tiêu chuẩn xuất bản, quản lý ấn phẩm khoa học, do đó GARP rất quan trọng với các tạp chí và trường đại học, chương trình nghiên cứu nhận kinh phí tài trợ từ chính phủ Ân Độ. Lẽ tự nhiên, các thông tin của GARP cũng rất hữu ích cho các nhà khoa học.

Ân Độ có tổng sản lượng kinh tế năm 2018 đạt trên 2700 tỷ USD. Mức chi tiêu chính phủ cho khoa học, bao gồm cả xuất bản khoảng 20 tỷ USD [2].

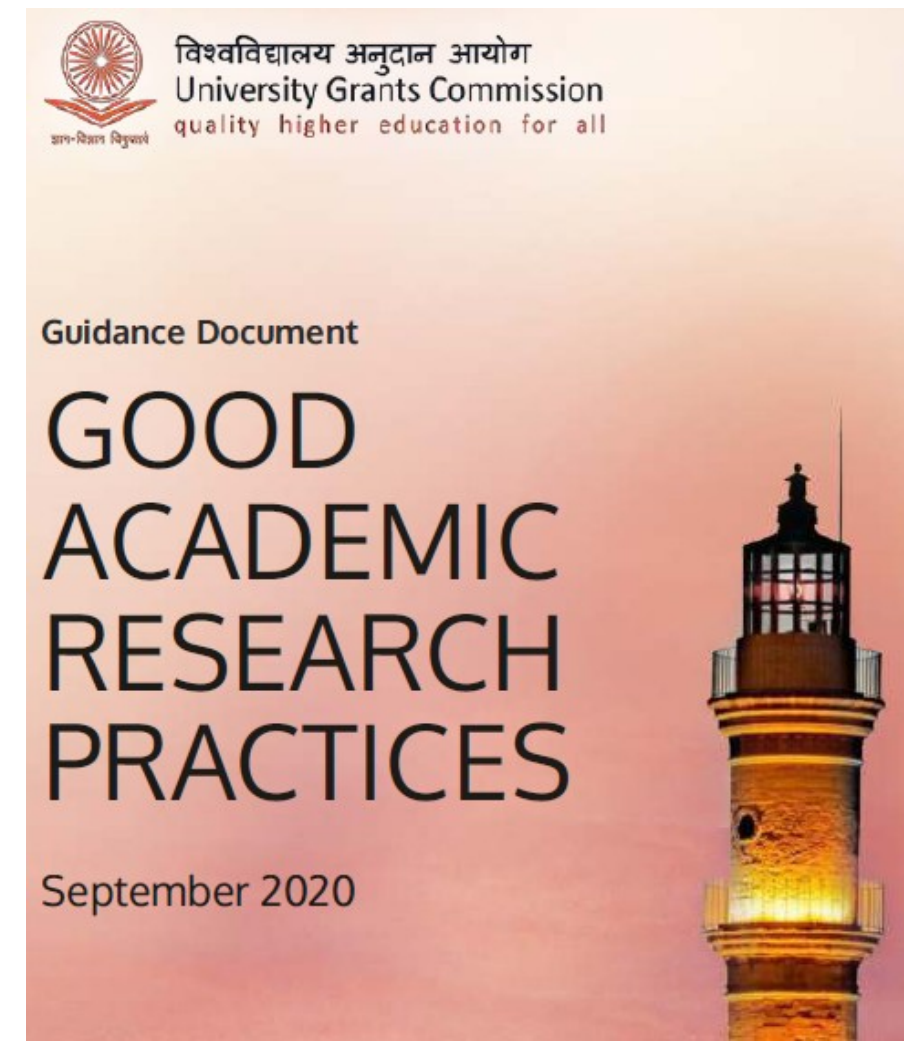


Ảnh bìa GARP 2020 của UGC; nguồn: https://www.ugc.ac.in/ebook/UGC_GARP_2020_Good\%20Academic\%20Research\%20Practices.pdf

Trong ấn phẩm GARP 2020, tài liệu [3] của tác giả Vương Quân Hoàng, Trung tâm ISR, đăng trên LSE Impact of Social Sciences được dẫn chiếu sớm cùng một số tài liệu quan trọng khác [4], cho cách hiểu về thực hành khoa học với việc liên tục cải thiện chất lượng nghiên cứu, và hiệu chỉnh khiếm khuyết với sản phẩm khoa học.

Việc tài liệu khoa học được sử dụng trong các chính sách quốc gia là một chỉ dấu về giá trị của tài liệu. Trong trường hợp cụ thể với GARP 2020, đó là chính sách khoa học và liên quan tới tài trợ khoa học thì ý nghĩa càng rõ rệt, nhất là với Ân Độ, một quốc gia lớn với nền khoa học phát triển và đang trên đà tăng trưởng nhanh.

\section{Tài liệu tham khảo:}

[1] Patwardhan B., Desai A., Chourasia A, Nag S., Bhatnagar R., 2020. Guidance Document: Good Academic Research Practices. New Delhi: University Grants Commission. < https://www.ugc.ac.in/ebook/UGC GARP 2020 Good\%20Academic\%20Research\%20Practices.pdf >

[2] Ministry of Science \& Technology. 2020. India's R\&D expenditure \& scientific publications on the rise. India is placed 3rd among countries in scientific publication. PIB PR (May 1, 2020) < https://pib.gov.in/PressReleasePage.aspx?PRID=1620083 >

[3] Vuong Q.H., 2020. Retractions: the good, the bad, and the ugly. LSE Impact of Social Sciences (Feb 20, 2020).

$<$ https://blogs.Ise.ac.uk/impactofsocialsciences/2020/02/20/retractions-the-good-thebadand-the-ugly-what-researchers-stand-to-gain-from-taking-more-care-tounderstanderrors-in-the-scientific-record/>

[4] Fang, F.C., Steen, R.G., and Casadevall, A., 2012. Misconduct Accounts for the Majority of retracted Scientific Publications. Proceedings of the National Academy of Sciences, 109(42):17028-17033. 